\title{
Kinesfields: transfiguring movement perceptions
}

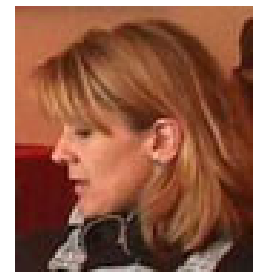

\section{Gretchen Schiller}

Université Paul Valéry, Montpellier III Bauff Centre for the Arts

gretchen.schiller@univ-montp3.fr

\begin{abstract}
Our sense of movement initiation across digitally and analog spaces is causing a paradigm shift in our inherited dance practice and terminology. Our previously described kinesphere is shifting to a spatially distributed and networked kinesfield. This is causing us to examine our physical rapport across space and within ourselves. This presentation will look at a taxonomy of movement inscription processes that have contributed to this shift both historically and in current artistic practice. Methods of decoding, representing, reproducing, translating and transfiguring movement and inscription will be discussed during the presentation with text and visual examples.
\end{abstract}

Historically, physiologists, choreographers, computer scientists and visual artists have attempted to capture bodily movements with visual inscriptions. These include graphic drawings, notations, and recorded representations of bodily movement in space. These representations capture the ephemeral nature of movement thereby making them available as artistic, educational and social artifacts.

In 1932 Rudolph Von Laban, a Hungarian born graphic artist and choreographer, began investigating ways of representing, defining, and notating bodily movement in space with language and symbols. Laban was driven to develop a language that would bridge the differences arising from the idiomatic nature of dancer's movements. He believed that there were underlying time, space, weight and flow principles at play that could be universally codified.

Laban was inspired by Raoul-Auger Feuillet's book Chorégraphie ou L'art de décrire la danse par caractères, figures et signes demonstratifs avec lesquels on apprend facilement de soi même toutes sortes de danses (Choreography or, the art of describing dance by characters, figures, demonstrative signs with which we can learn all forms of dance by oneself) published in 1700 (Maletic, 1950, p. 5). He based his own notation and movement analysis on Feuillet's transfer of weight and directional movements in space. Laban developed an extensive vocabulary for movement tensions in space and defined the invisible bubble that surrounds one's body as a kinesphere.

The usual reach of our limbs, when they stretch away from our body with out changing stance, determines the natural boundaries of the personal space or 'kinesphere' in which we move. This kinesphere remains constant in relation to the body even when we move away from the original stance; it travels with the body in the general space... This inhabited space or spatial crystal is the medium in which the structural tension of man is built (Maletic, 1950) ${ }^{[1]}$.

As Laban suggests, it is impossible to dissociate the body from its impact in 
space: together they create a medium. There are choreographers that investigate how Laban's notion of this medium, with its properties of time, space, weight and flow efforts, can be inhabited and altered in interactive installations. The interactive installations are choreographed and designed with movement knowledge, architecture, mechanics, digital media, electronics and computer science. In such practice, the choreographer invites a "non" trained dancer to inhabit an altered sense of embodiment and movement communication in a constructed and mediated space.

In the interactive movement installations presented here the bodymedium oscillates between levels of perception and action. Here the bodyspace medium of the participant is transformed beyond Laban's notion of the kinesphere. The participant or body-subject moves and actively sees changes in a given image, sound, interface or environment building a relationship between one's kinesphere and the general space outside one's kinesphere. This research proposes to call this bodyspace medium a kinesfield. A kinesfield is a perceptual shift from our inherited bodyspace definition of the kinesphere. It is dependent on body subjectivity co-inhabited with digital and telecommunication technologies. With the mediation of the computer, telecommunication and data processing technologies, dance artists can couple expression and inscription not only to record dance, but to create body-space interactions that are co-dependently expressive and informative. This is not simply a recording of movement, but an intentional, conditional and relational interplay between movement (or experience), and inscription (or representation). Such interaction transforms our sense of embodiment and challenges our relationships with spatial tensions and identification of the bodyspace as medium.

In these interactive movement based installations, the visitor, becomes as German philosopher and researcher Barbara Becker describes, the "bodysubject". Here the participant or body-subject receives, transmits and enacts movement knowledge. One becomes aware of this transfer of movement by actively sensing or seeing changes in a given interface or environment. Sound, light, movement images, and screens all contribute to the moving environment which itself constitutes an ecosystem or a context. The physical participation of the body-subject in this space invites physical and mental transformation and awareness. When movement inscription is integrated with the movement, the body-subject is "entertrained" (entertained and trained) with intentional mediated movement response, guidance or information.

Certain computer-assisted movement techniques serve as kineasthetic sensory tools that transform and couple our bodyspace participation and perception. These tools, once coupled with human movement resemble sensory organs that transform our sense of being in the world. These tools amplify and privilege specific movement perception while limiting others. Historically, they have been used in the following way.

1. To measure physical properties of movement.

2. To represent movement with the intent of recording movement.

3. To translate one symbolic system into another symbolic.

4. To interpret: to reference one symbolic system into another.

5. To transfigure or transform bodily movement with feedback. 


\section{Notes:}

[1] MALETIC, Vera. (1987). Body space expression: the development of Rudolf Laban's movement and dance concepts. Berlin, Germany: Mouton de Gruyter

\section{Related Links:}

Gretchen Schiller

http://www.caiia-star.net/people/Gretchen-Schiller/index.html

Shift

http://www.caiia-star.net/people/Gretchen-Schiller/shift.html

Trajects

http://ccii.banff.org/trajets/

[Published on: december 2001]

(c) Gretchen Schiller, 2001

Recommended citation:

SCHILLER, Gretchen (2002). "Kinesfields: transfiguring movement perceptions". Artnodes, issue 1 [article online].

DOI: http://dx.doi.org/10.7238/a.v0i1.671 